\title{
Assessing the Enduring Impact of Library Instruction Programs
}

by Gabrielle Wong, Diana Chan, and Sam Chu

Gabrielle Wong, Reference Librarian, The Hong Kong University of Science and Technology Library, Clear Water Bay, Kowloon, Hong Kong

$<$ lbgabi@ust.hk>

Diana Chan, Head of Reference, The Hong Kong University of Science and Technology Library, Clear Water Bay, Kowloon, Hong Kong

$<$ lbdianac@ust.hk>

Sam Chu, Assistant Professor, Division of Information \& Technology Studies, Faculty of Education, The University of Hong Kong, Pokfulam Road, Hong Kong

<samchu@hku.hk.> 


\begin{abstract}
In order to improve library instruction and to produce data that shed light on the value of this core library service, the Hong Kong University of Science and Technology Library conducted a formal assessment on its instruction program in 2004. A group of 688 users from 25 one-shot sessions was surveyed by a questionnaire four to eight weeks after the sessions were conducted. Results showed that the majority of attendees remained positive about the usefulness of the library sessions; they retained and used the skills learned; the overall rating of the library sessions and the instructors were comparable to those of the University's credit course ratings.
\end{abstract}

\title{
INTRODUCTION
}

Libraries worldwide have to face a growing call for assessment. As a core library service, library instruction has naturally become a primary candidate for performance measurement. Evaluating the results of library instruction is not always a simple task. Library classes are usually wideranging in scope and content. Also, librarians do not have stable groups of students to assess. As Rabine and Cardwell point out, "librarians do not have steady contact with the same students over a period of years, with the many opportunities for instruction that would imply." ${ }^{1}$ One-shot classes make evaluation even trickier. Any effort to measure the impact of such brief contact with students is bound to be a challenge.

Despite these potential challenges, librarians at the Hong Kong University of Science and Technology (HKUST) made their first attempt at a formal assessment of the library instruction program by conducting a survey of library class attendees in 2004. The results demonstrate the value of the program, and provide insights for improvement.

\section{LIBRARY INSTRUCTION AT HKUST}

HKUST is a young research university which opened in 1991. It has a current student body of 8,500 engaged in over 100 degree programs, including 25 doctoral programs, in science, engineering, business \& management, humanities, and social sciences. The University Library is located centrally on campus with a collection of over 700,000 print items and approximately 16,000 electronic titles. Its library instruction program serves the whole university community, including all students, faculty, and staff. The great majority of the classes offered are one-shot sessions of 50 to 80 minutes. They encompass a wide variety of library instruction covering information tools and search techniques: first-year students' orientation, library classes associated with specific courses, database workshops, research workshops for postgraduates, and general research skills such as job hunting and use of microforms. In the 2004/05 academic year, 179 classes were held with 4,223 attendees, most of whom were students.

As an ongoing practice, library class participants are asked to complete a brief, standardized evaluation form at the conclusion of the class. The form solicits the attendees' feedback, their perception on the class content and the instructor, and whether the class is worth recommending to their peers. Such feedback is usually positive: a sample of nine orientation classes (119 students) for first-year students in 2002/03 showed that $88 \%$ of the students either "strongly recommended" or "recommended" the class to others, and $81 \%$ rated the instructor as "excellent" or "good". Although this evaluation practice provides immediate feedback for individual instructor's reference, the results have never been reviewed systematically. More importantly, it offers no insight into what these seemingly satisfied attendees have gained from the class. How much have they learned? 
What do they think of these classes after a few weeks? Do the classes exert any lasting impact on them? In other words, does the HKUST Library instruction program have any enduring value? As Pausch and Popp put it succinctly, librarians want to find out "whether or not what is taught is useful and has carryover from the initial session to at least the end of the student's studies." ${ }^{2}$ In this context, the University Librarian, Dr. Samson Soong, urged the Reference Department to embark on a project that could assess its library instruction at a programmatic level. It was envisioned to be a formal assessment for program improvement, and at the same time yield data that have the potential to demonstrate the value of the program.

The goals of the project are:

1. to measure any enduring impact of the library instruction program on users' learning and research;

2. to collect data and comments so as to improve the quality of the program.

\section{ASSESSMENT METHODS IN LITERATURE}

A literature review proves that library instruction assessment has been prevalent in colleges and universities; however, relatively few institutions have conducted assessments on a programmatic level, and even fewer focus on the enduring impact of library instruction.

In 1981, King and Ory categorized evaluation methods into three approaches: determining knowledge and skills by tests, determining opinions by perceptual evaluation, and determining library use. ${ }^{3}$ Each approach has its strengths and limitations, and most assessment projects use survey methods that adopt one or a combination of them.

In the 1990s, an increasing emphasis fell on outcomes assessment. With the need to produce "hard data" to demonstrate the value of instruction programs, summative assessment that measures the effect of library instruction in a quantitative manner became a more popular approach. One can see the trend of focusing on the "test" component in the survey instrument. Many use a pre/post-test to measure the changes imparted by the library instruction effort. In fact, many of the pre/post-test surveys do not exclude the "perception" component or the "use" component. Barclay, for instance, combined a test with an opinion survey in his simple but effective study. ${ }^{4}$ His pragmatic approach of "doing the best you can with what you have" was echoed by many.

Towards the end of 1990s, Colborn and Cordell called for a more objective analysis of librarians' teaching, and developed a pre/post-test that was administered on a sample of 404 students from a freshman course. ${ }^{5}$ Despite a very rigorous development process, the test produced data that showed no significant difference between the pre- and post-test results. Similarly, Riddle and Hartman applied a pre/post-test to evaluate their 80-minute library class supporting a rhetoric course, but with a good sample size of 1,197 completed questionnaires, their study successfully "indicated that the library classes measurably improved the library skills of the students." 6

Other than survey methodologies, librarians have explored other innovative and sophisticated ideas in 2000s. Rabine and Cardwell reported their assessment strategies for both program and classroom levels. A student library skills assessment survey, called mini-quiz, was used to assess program-level outcomes on a large scale. The quiz contained questions on basic concepts of library use; it was not tied up to particular library classes. Comparisons were made between first-year and fourth-year students, and between students who were exposed to certain library instruction and those who were not. Differences were observed, but few were statistically significant. On the other hand, at the class-level, a four-part assessment tool was adopted for the one-shot sessions. ${ }^{7}$ This 
approach was effective, but time-consuming; librarians were asked to use this tool with only one class per semester.

Moore, Brewster, Dorroh and Moreau studied the impact of their library information competency program on student success in other classes. They compared the GPA of the students who attended the classes and those who did not. ${ }^{8}$ "While the data did show a positive correlation between the library course and grade point averages of the students, the data were too small to be significant." 9

Along the same line, Emmons and Martin compared the research papers of a first-year English course before and after the implementation of the library instruction program. The students' papers were studied meticulously, but it was found that the library program made a small difference in the types of materials students chose and how they found them. ${ }^{10}$

Besides the instrument employed in the study, librarians at HKUST were also interested in the timing of the survey so as to measure the enduring effect of its instruction program. Orme conducted the assessment one semester behind the library instruction. His aim was to assess the residual impact on the improvement of first-year students' information-seeking skills, and to investigate whether persistent learning has been taking place. ${ }^{11}$ Other examples of "delayed" survey include King and Ory ${ }^{12}$ and Colborn and Cordell ${ }^{13}$.

The challenge for the Reference team at HKUST was to design a valid and effective assessment that evaluates the whole instruction program, without posing rigorous demands on the attendees and the teaching librarians. The assessment should be easy to implement, and capable of repetition and modification. The Reference team shortlisted the pre/post-test approach and the perception survey approach for final consideration. The appeal of the pre/post-test is that it seems to be a more accurate measure of what students have actually learned. However, this outcome-specific approach is undoubtedly class-specific. At HKUST, where the library instruction program is composed of a wide array of one-shot sessions that have different teaching objectives and cover different library skills, the test approach would not serve the purpose of performing a programmatic assessment. In the end, the Reference team decided to adopt a perception survey.

\section{METHODOLOGY}

\section{A Delayed Survey}

As an attempt to measure the enduring impact of library instruction, the Reference team decided that the survey should be administered some time after the classes were conducted, to allow the attendees to apply the library skills learned to their projects or assignments, hence reinforcing the skills as well as their perception of the library session, or, on the contrary, to allow attendees to see the weaknesses or inadequacies of the library session.

A delay period of four to eight weeks was agreed upon as an appropriate length for the enduring impact to be observable. This range also gave flexibility to credit course professors to find a convenient time to help the librarians distribute the questionnaires to their classes. 


\section{Questionnaire Design}

A two-page questionnaire (Appendix) was designed by a subgroup of four reference librarians; it should take the attendees no more than five minutes to complete, but should allow the librarians to: 1. find out if and how the attendees were changed by the class (Question 2 and 3);

2. find out whether they retained and continued to use the learned skills after a period of time (Question 4);

3. assess the quality of the class content and the instructor perceived by the attendees after a period of time (Question 5 and 6);

4. solicit attendees' suggestions for improvement. (Question 7)

In Question 2, attendees were asked to rank their perception on a Likert scale with four points, forcing them to choose either the agree side or disagree side.

For Question 5 and 6, the Reference team followed the model of the University's credit course evaluation. HKUST uses a standardized form to evaluate courses from all schools at the end of the semesters. That questionnaire uses a seven-point scale, from 0 (Very Bad) to 6 (Very Good), to rate the class and the instructor. For the purpose of using the credit course evaluation result as a benchmark, this questionnaire also adopts the same scale for Question 5 and 6.

\section{Sampling}

Library classes offered in HKUST Library may be categorized into course-specific (CS) and open workshop (OW) ones. The former supports the information requirements of specific courses, while the latter is open to all users. Database workshops, job hunting workshop and Web searching workshops belong to the OW category.

All the eight librarians who had shared teaching duties were asked to nominate their classes for the survey. For a CS session to be selected, it should preferably be project- or assignment-based. A good candidate should also have a class size of 15 or above to ensure a reasonable sample size.

The sample consisted of users who registered to attend the selected open workshops, or students taking specific courses for which library workshops had been arranged. In Fall 2004, librarians at HKUST conducted a total of 133 instruction sessions. The survey enlisted 25 sessions, comprising $15 \mathrm{CS}$ and $10 \mathrm{OW}$ sessions. (Table 1)

[Table 1]

\section{Administration of the Survey}

The questionnaires for all but one CS session were sent out in print format and were distributed by the credit course instructors during their class time. Since all OW attendees used email to sign up the workshops, the email lists were used to deliver the email questionnaires. One CS session also used email questionnaires. 


\section{Data Analysis}

The results were coded and entered into SPSS for statistical analysis.

The CS and OW groups differ in many ways: respondents' background, class objectives, how they signed up and how they were surveyed. It is therefore more meaningful to analyze the two groups separately. Comparing the results from them also helps librarians understand their users and reflect on the different treatment of these two types of library instruction efforts.

\section{Response Rate and Respondents' Characteristics}

The survey had a response rate of $68 \%$ with 466 replies. The respondents came from all four schools at HKUST: Engineering 45\%, Business \& Management 35\%, Science 14\%, and Humanities \& Social Sciences 6\%. Among them, 82\% were undergraduates, $11 \%$ were postgraduates, while faculty and staff made up 3\%, and $4 \%$ were exchange students. The ratio of male to female was about $6: 4$. About $11 \%$ of the respondents were absent from the library sessions, and they only answered questions on demographics and information use habit.

The group of CS respondents had a heavy representation (82\%) of undergraduates from Hong Kong while the OW group was more diversified in background.

Half of the respondents had to search information sources for assignments or projects over seven times in the past year. About $45 \%$ of the respondents had attended two to three library classes. During their life at HKUST, $63 \%$ of the respondents indicated that they were confident or very confident in doing library research. The responses reveal that the group of respondents who had never attended any library classes had a higher proportion on the "not confident" side (Figure 1). A chi-square test confirmed that the two variables, namely the number of classes attended and the information research confidence, are not independent $\left(\chi_{\text {observed }}^{2}=16.739 ; \chi_{\text {critical } \alpha=.05, \mathrm{df}=6}^{2}=12.5916\right.$; $\mathrm{p}=0.01)$.

[Figure 1]

\section{FINDINGS}

The survey results were encouraging and insightful. It affirmed the value of the library classes and provided some useful suggestions for program improvement. Analysis showed that most attendees agreed that the library class had helped them and many continued to use the skills learned after the delay period. The OW group was consistently and significantly more positive than the CS group.

\section{Impact of Library Classes}

In Question 2, over 85\% of the attendees agreed on the usefulness (part a-c) of the sessions. Well over half agreed that the class increased their confidence in information searching and increased their interest in using the Library (Table 2). It is interesting to observe that the mean scores decreased from part a to part e. This may be interpreted as that users perceived the classes as having a higher impact on them in terms of practical usefulness rather than raising their confidence in information search or interest in using the Library.

[Table 2] 
The mean scores of OW, all above three, are consistently higher than those of CS (Table 3). The differences were run through an independent samples t-test and were found to be statistically significant (at 95\% confidence level). This observation is hardly surprising. The OW group took the workshops on a voluntary basis; the fact that they chose to come and chose to reply to the email questionnaire is indicative of their level of motivation. With a relatively high proportion of postgraduates and university staff, the OW group was more mature and appreciative of the Library's effort. The CS group, on the other hand, attended the classes as a requirement of their courses. This "compulsory" element might have negatively affected their perception of the library classes.

[Table 3]

\section{Skills that Attendees Learned from the Class}

Question 3 asked the respondents to self-evaluate what they had learned. On average, each attendee marked 2.06 choices from the list. The top two choices were "Form better search strategies" and "Find more relevant internet resources".

\section{Skills Retention and Applications}

A potent indicator of the enduring value of the library classes is whether the attendees retain and continue to apply the skills acquired. Question 4 asked if the respondents continued to use the skills learned. For the purpose of discussion, the percentage of respondents answering "Yes" to this question is defined as the "Retention Rate".

The sample had a Retention Rate of $68.5 \%(\mathrm{~N}=397)$. The rates of CS and OW were almost identical (68.5\% and 68.4\%). An in-depth analysis reveals a more detailed picture. Table 4 shows the Retention Rates of 23 sessions. Over half of the sessions scored better than the mean; 15 out of 23 had over $70 \%$ of attendees continuing to use the skills.

The Retention Rate of OW ranged from $56 \%$ to $83 \%$, with the highest number of sessions falling in the $70 \%-79 \%$ notch while CS had a wider range from $50 \%$ to $100 \%$, and the highest number of sessions falling in the $80 \%-90 \%$ notch. All the CS sessions served the information needs of particular courses for assignments or projects. It was therefore reasonable, and also encouraging to know that all attendees in two CS sessions retained and applied the skills after the classes.

Nevertheless, the CS group comprised classes from various disciplines, each with a different weighting on the information research component of their assignments or projects. The Reference team believes that the wider range of Retention Rate in CS was attributed to the varied nature of the assignments or projects. Although all sessions taught basic concepts in information literacy in a wider context, attendees apparently only retained and applied the information skills upon motivation by actual coursework requirements.

On the contrary, attendees of OW did not have any associated coursework to complete. The Reference team took it as a positive indication that the mean of OW was still comparable to that of CS.

\section{[Table 4]}

To strive to raise the skills retention, the Reference team looked into the written comments of attendees who did not continue to use the skills. About half of those comments stated that there was no need or chance to apply the information skills. A few also reported that they had forgotten what they had learned. These comments provide food for thought. The teaching librarians should 
reflect on the timing and content of the classes in relation to attendees' information need, as well as development of effective teaching skills that enhance attendees' retention. Class promotion materials for OW should also be better designed so as to attract users whose information need matches the coverage of the workshops.

\section{Class Rating and Instructor Rating}

Attendees rated the class and the instructor on a seven-point scale ("Very bad", "Bad", "Below Average", "Average", "Above Average", "Good" and "Very good"). Overall, attendees rated both the class and the instructor higher than the "Above Average" mark. OW again gave considerably higher ratings: both were above the "Good" mark. Table 5 shows the scores converted in the same manner as the University's credit course evaluation ("Very bad" $=0$, "Very good" $=100$ ).

\section{[Table 5]}

The average ratings of medium-sized credit courses (class size of 20-100) at HKUST in the same semester are listed in Table 6 for comparison.

The Library's scores are generally comparable to those of the credit courses. The CS ratings are lower than those of the undergraduate course while the OW ratings are higher than the scores of both the undergraduate and postgraduate courses.

[Table 6]

Table 7 shows the ratings with the "neutral" opinions removed. There was $4-6 \%$ of CS who felt negative towards the instructor or the class, but no one in OW felt that way. This is an encouraging sign indicating that the OW group was satisfied with the sessions.

[Table 7]

\section{Suggestions for Improvement}

As Barclay (1993) contended, "[u]nless evaluation will somehow improve the thing being evaluated, it is not worth doing" (p. 199). A major goal of this assessment is to solicit concrete feedback from attendees on how the library classes could do better (Question 7). The survey results indicated that attendees would prefer shorter, smaller classes and more hands-on practice during the session. Written comments also called for materials to be covered in more detail, and more class handouts.

\section{Effect of Class Size}

Various factors interplayed to influence the outcome of the classes. The number of participants in a session was among the major ones. "Retention Rate", "Class Rating" and "Instructor Rating" were analyzed to reveal the effect of class size. To focus on how class size affects the attendees' responses, only CS was included in this part of the analysis.

By inspecting the scattered plots, one can see that the negative effect of class size on the outcome was most visible with "Retention Rate" (Figure 2). The "Class Rating" and "Instructor Rating" also show a trend of declining while class size increases. (Figure 3 and 4)

[Figure 2, 3, \& 4] 


\section{Information Research Confidence and Perception of the Library Classes}

Attendees who were more confident in information research gave more positive responses in the three major indicators: "Retention Rate", "Class Rating" and "Instructor Rating" (Figure 5-7). It was worth noting that all the nine respondents in CS who ranked themselves as "Not at all confident" claimed that they did not continue to use the skills learned while all the five respondents in OW who were "Very confident" said they retained the skills.

A similar trend in "Class Rating" and "Instructor Rating" was observed by inspection when the data was coupled with the "Number of Library Classes Attended". Frequent library class participants tend to give higher ratings for both categories. Nevertheless, this trend did not repeat itself at "Retention Rate".

[Figure 5-7]

\section{Actions Suggested by Findings for Future Assessment}

Assessment of the library instruction program is at its infancy at HKUST Library. A more refined assessment plan is essential for the Library to achieve continuous and measurable improvement. The Reference team is already committed to repeating the survey in the academic year of 2006/07.

A few changes may be made to strengthen and enhance the assessment in the next run:

1. Quantify the changes over the delay period

The evaluation form that has been in use for immediate feedback will be redesigned to fall in line with the delayed survey questionnaire, so that the differences in responses can be quantified and analyzed to assess if the gain from the library class lasts.

2. Learn more about the users

Analysis can be done to examine differences between different groups of attendees. For example, teaching librarians at HKUST have always believed that postgraduate students or students from Mainland China are more receptive to the instruction efforts than undergraduate students and local Hong Kong students respectively. More data will be needed to substantiate this conjecture.

\section{Separating CS and OW}

As the two groups showed significant differences in the responses, different assessment methods may be adopted. In addition, more OW sessions would be enlisted to create a more balanced sample of CS and OW attendees.

\section{SUMMARY \& CONCLUSION}

At HKUST Library, at the urge of the University Librarian, the Reference team took an exploratory but important step to assess the enduring value of the library instruction program that is composed of a wide variety of one-shot sessions to a diverse user group. After balancing the resources and time available, and considering the characteristics of the library instruction program as well as the users at HKUST, the team adopted the methodology of a "delayed" perception survey which was administered four to eight weeks after the classes. The survey produced these indicative figures:

- Over $85 \%$ of the attendees remained positive about the usefulness of the classes by stating that they learned where and how to find information efficiently.

- Most attendees agreed that they learned how to form better search strategies and how to find relevant internet resources.

- Almost $70 \%$ of the attendees retained the skills learned. 
- Class Ratings and the Instructor Ratings were around 70, comparable to the equivalent ratings of the University's credit courses.

Data like these show the value of the instruction program and may be used by the Library administration to demonstrate accountability and service value to the University. Besides yielding data, the survey findings also suggested ways for improvement that would definitely bring changes to future library classes:

- shorter classes

- smaller classes

- more hands-on practice

- better class handouts

Written comments on attendees' skills retention and application further inform the teaching librarians to investigate ways to raise attendees' attention:

- better coordination in class schedule and timing in respect of students' information needs

- innovative teaching strategies that are conducive to effective learning and knowledge retention

\section{How Teaching at HKUST Was Affected By the Survey}

Based on the suggestions from the survey, HKUST librarians have taken steps to improve their classes. Most librarians reconsidered the length of the sessions and the content of the handouts. For instance, one librarian reduced the length of a MBA class from 80 to 60 minutes. The evaluation on this class proved that this was a well-received change. Another librarian split a large class of 60 students into two groups, so that each student could benefit from hands-on practice. As an attempt to increase skill retention by enhancing interactivity during the session, one librarian used the Personal Response System (PRS) developed by HKUST that facilitates instant feedback in classrooms. A series of multiple-choice questions were projected on the screen; students answered them by making their choices on the wireless, hand-held PRS transmitters. Their responses were immediately analyzed and tabulated on the screen. This was a large lecture class without hands-on, but the PRS provided a channel for students to interact with the instructor.

\section{Conclusion}

Assessment of a library instruction program is a daunting task. Using Colborn and Cordell's words, "this is rarely done because there are no perfect measures, and there is relatively little reward for undertaking such an enormous task." ${ }^{14}$ Nevertheless, librarians should not be deterred. This firsttime assessment attempt by HKUST librarians employed a practical and manageable methodology; data are analyzed in a straight forward manner. Not only had it achieved its goals, it also laid a solid basis for future endeavors of its kind.

Through this exploratory effort, HKUST librarians have made strides on assessing the library instruction program. By working towards a robust assessment plan, the Reference team hopes that the practice of performance measurement will help us achieve an end, that is, to enhance teaching and learning in the Library.

Acknowledgements: The authors would like to thank Dr. Samson Soong (University Librarian, HKUST), Ms. Catherine Kwok and Mr. Wing Kee Ho (both are Reference Librarians, HKUST) for providing valuable comments on this paper. 


\section{NOTES AND REFERENCES}

1. Julie Rabine and Catherine Cardwell, "Start making sense practical approaches to outcomes assessment for libraries," Research Strategies 17 (2000): 320.

2. Lois M. Pausch and Mary Pagliero Popp, "Assessment of information literacy: lessons from the higher education assessment movement," (paper presented at the 1997 ACRL National Conference, Nashville, Tennessee) Available:

http://www.ala.org/ala/acrlbucket/nashville1997pap/pauschpopp.htm (accessed Sept 14, 2005).

3. David N. King and John C. Ory, "Effects of library instruction on student research: a case study," College and Research Libraries 41 (January 1981): 31-41.

4. Donald Barclay, "Evaluating library instruction: doing the best you can with what you have," RQ 33 (1993): 195-202.

5. Nancy W. Colborn and Rossane M. Cordell, "Moving from subjective to objective assessments of your instruction program," Reference Services Review 26 (Fall/winter 1998): 125-137.

6. John S. Riddle and Karen A. Hartman, "But are they learning anything? Designing an assessment of first year library instruction," College \& Undergraduate Libraries 7 (2000): 66.

7. Rabine and Cardwell, "Start making sense practical approaches to outcomes assessment for libraries."

8. Deborah Moore, Steve Brewster, Cynthia Dorroh and Michael Moreau, "Information competency instruction in a two-year college: one size does not fit all," Reference Services Review 30 (November 2002): 300-306.

9. Ibid., p. 301.

10. Mark Emmons and Wanda Martin, "Engaging conversation: evaluating the contribution of library instruction to the quality of student research," College and Research Libraries 63 (November 2002): 545-560.

11. William A. Orme, "A study of the residual impact of the Texas Information Literacy Tutorial on the information-seeking ability of first year college students," College and Research Libraries 65 (May 2004): 205-215.

12. King and Ory, "Effects of library instruction on student research: a case study."

13. Colborn and Cordell, "Moving from subjective to objective assessments of your instruction program."

14. Ibid., p. 126. 


\section{香港科技大學圖 書館 Hong Kong University of Science es' Technology Librany}

\section{Library Class Survey}

Purpose: This survey is designed to help us understand how useful the Library classes are in the long term. Your participation will help us to plan and modify our classes to better serve our users. There are no right or wrong answers. This will take you less than 5 minutes.

1. Did you attend the library class of XXX on DATE?

$\square$ Yes (Go to question 2)

$\square$ No. I did not attend the class because 0

$\square$ I forgot to attend $\mathrm{b5}$

$\square$ I already had attended a library class that covered similar material $b 4$

$\square$ I already knew the material that the library class covered ${ }_{b 3}$

$\square$ I was too busy b2

$\square$ Others b1

(Go to question 8)

2. As a result of the class, I

a. learned about sources to find needed information.

b. learned about search methods to find needed information.

c. learned how to find needed information more quickly.

d. was more confident in researching information.

e. have increased my interest in using the Library.

\section{Strongly Agree Disagree Strongly \\ Agree \\ Disagree}

$\begin{array}{llll}\square_{4} & \square_{3} & \square_{2} & \square_{1} \\ \square_{4} & \square_{3} & \square_{2} & \square_{1} \\ \square_{4} & \square_{3} & \square_{2} & \square_{1} \\ \square_{4} & \square_{3} & \square_{2} & \square_{1} \\ \square_{4} & \square_{3} & \square_{2} & \square_{1}\end{array}$

3. Please indicate the skills in which this class has helped you (you may check more than one item):

$\square$ Choose the best databases for my information need ${ }_{a}$

$\square$ Form better search strategies ${ }_{b}$

$\square$ Select more appropriate keywords to search $c$

$\square$ Export or save my results more effectively ${ }_{d}$

$\square$ Find more relevant internet resources ${ }_{\mathrm{e}}$

$\square$ Use printed resources more effectively ${ }_{f}$

$\square$ Others

4. Have you continued to use the skills that you learned in this class?

$\square$ Yes, please specify

$\square$ No, please specify

5. What is your OVERALL rating of the class:

$\square$ Very $\operatorname{good}_{6}$

$\square$ Good $_{5}$

$\square$ Above average $_{4}$

$\square$ Average $_{3}$

$\square$ Below average $_{2}$

$\square \mathrm{Bad}_{1}$

$\square$ Very bad 0 


\section{Table 1}

Examples of Classes Selected for the Survey

Course-specific (CS)

CENG 297 / Chemical Engineering Lab

MGTO 331 / Entrepreneurship \& Small Business Studies

SOSC 511 / Social Research Methods

\section{Open workshops (OW)}

Resources on Job Hunting

ProQuest workshops

Web of Science workshops

\section{Table 2}

Responses to Question 2 on a 4-point scale (1: Strongly Disagree, 4: Strongly Agree)

Question 2: As a result of the class,...

a. I learned about sources to find needed information $(\mathrm{N}=412)$

b. I learned about search methods to find needed information $(\mathrm{N}=412)$

c. I learned how to find needed information more quickly $(\mathrm{N}=409)$

d. I was more confident in researching information $(\mathrm{N}=410)$

e. I have increased my interest in using the Library $(\mathrm{N}=412)$

\begin{tabular}{ccc}
$\begin{array}{c}\text { Mean Score } \\
3.15\end{array}$ & $\begin{array}{c}\text { Agree \% } \\
95.6\end{array}$ & $\begin{array}{c}\text { Disagree \% } \\
4.4\end{array}$ \\
3.12 & 93.0 & 7.0 \\
3.04 & 85.3 & 14.7 \\
2.85 & 74.1 & 25.9 \\
2.68 & 61.2 & 38.8 \\
\hline
\end{tabular}

Table 3

Comparing CS and OW in the Responses to Question 2

\begin{tabular}{|c|c|c|c|c|l|l|c|}
\hline & \multicolumn{2}{|c|}{ CS } & \multicolumn{2}{c|}{ OW } & \multicolumn{2}{c|}{ t-test for Equality of Means } \\
\hline & Mean Score & Agree \% & Mean Score & Agree \% & $\mid \mathbf{t}_{\text {observed }}$ & $\mathbf{t}_{\text {critical }(\boldsymbol{\alpha}=\mathbf{0 5})}$ & $\mathbf{p}$ \\
\hline a & $3.09(\mathrm{~N}=354)$ & 95.2 & $3.52(\mathrm{~N}=58)$ & 98.2 & 5.70 & 2.00 & $<.0005$ \\
\hline b & $3.06(\mathrm{~N}=354)$ & 91.8 & $3.50(\mathrm{~N}=58)$ & 100 & 6.25 & 2.00 & $<.0005$ \\
\hline c & $2.98(\mathrm{~N}=354)$ & 84.8 & $3.38(\mathrm{~N}=55)$ & 89.1 & 4.12 & 2.00 & $<.0005$ \\
\hline d & $2.80(\mathrm{~N}=353)$ & 72.2 & $3.16(\mathrm{~N}=57)$ & 85.9 & 4.04 & 1.98 & $<.0005$ \\
\hline e & $2.59(\mathrm{~N}=354)$ & 57.9 & $3.21(\mathrm{~N}=58)$ & 81.6 & 6.28 & 1.98 & $<.0005$ \\
\hline
\end{tabular}

\section{Table 4}

Percentages of Positive Responses to Question 4 by Sessions $(\mathrm{N}=394)$

\begin{tabular}{ccccc}
\hline Percentage of Answer "Yes" to Q. 4 & No. of Sessions & CS & OW & Cumulative Count \\
\hline $100 \%$ & 2 & 2 & 0 & 2 \\
$90-99 \%$ & 0 & 0 & 0 & 2 \\
$80-89 \%$ & 6 & 5 & 1 & 8 \\
$70-79 \%$ & 7 & 4 & 3 & 15 \\
\hline $60-69 \%$ & 3 & 2 & 1 & 18 \\
$50-59 \%$ & 5 & 3 & 2 & 23 \\
\hline Total number of sessions analyzed: & $23^{*}$ & & & \\
\hline
\end{tabular}

*Two sessions were excluded as too few responses were received. 


\section{Table 5}

Question 5 and 6: Class Rating and Instructor Rating by Class Types

\begin{tabular}{llccc}
\hline & & No. of respondents (N) & Mean & Std. Deviation \\
\hline Class & CS & 353 & 66.34 & 17.25 \\
& OW & 57 & 84.21 & 12.76 \\
Instructor & CS & 344 & 69.19 & 17.82 \\
& OW & 57 & 85.38 & 12.23 \\
\hline
\end{tabular}

The scale for rating the University credit courses: Very Good $(=100)$, Good (=83.3), Above Average $(=66.7)$, Average (=50), Below Average (=33.3), Bad (=16.7), Very Bad (=0)

\section{Table 6}

Ratings of HKUST Credit Courses in Fall 2004

\begin{tabular}{lcc}
\hline & Undergraduate courses & Postgraduate courses \\
\hline Class & 70.2 & 75.1 \\
Instructor & 72.4 & 78.5 \\
\hline Source: HKUST Course Evaluation Results, from & 7 Oeffice of the Vice-President for Academic Affairs
\end{tabular}

Source: HKUST Course Evaluation Results, from The Office of the Vice-President for Academic Affairs

\section{Table 7}

Question 5 and 6: Number of Respondents Having Positive or Negative Rating

\begin{tabular}{ccccc}
\hline & \multicolumn{2}{c}{ Class } & \multicolumn{2}{c}{ Instructor } \\
\hline & "Good" or "V. Good" & $\begin{array}{c}\text { "Below Average" } \\
\text { or lower }\end{array}$ & $\begin{array}{c}\text { "Good" or "V. } \\
\text { Good" }\end{array}$ & $\begin{array}{c}\text { "Below Average" } \\
\text { or lower }\end{array}$ \\
\hline CS & $115(33 \%)$ & $22(6 \%)$ & $141(41 \%)$ & $15(4 \%)$ \\
OW & $46(81 \%)$ & 0 & $45(79 \%)$ & 0 \\
\hline
\end{tabular}

\section{Figure 1}

Distribution of Responses in Information Research Confidence, analyzed by Respondents' BI Experience ( $\mathrm{N}=444)$

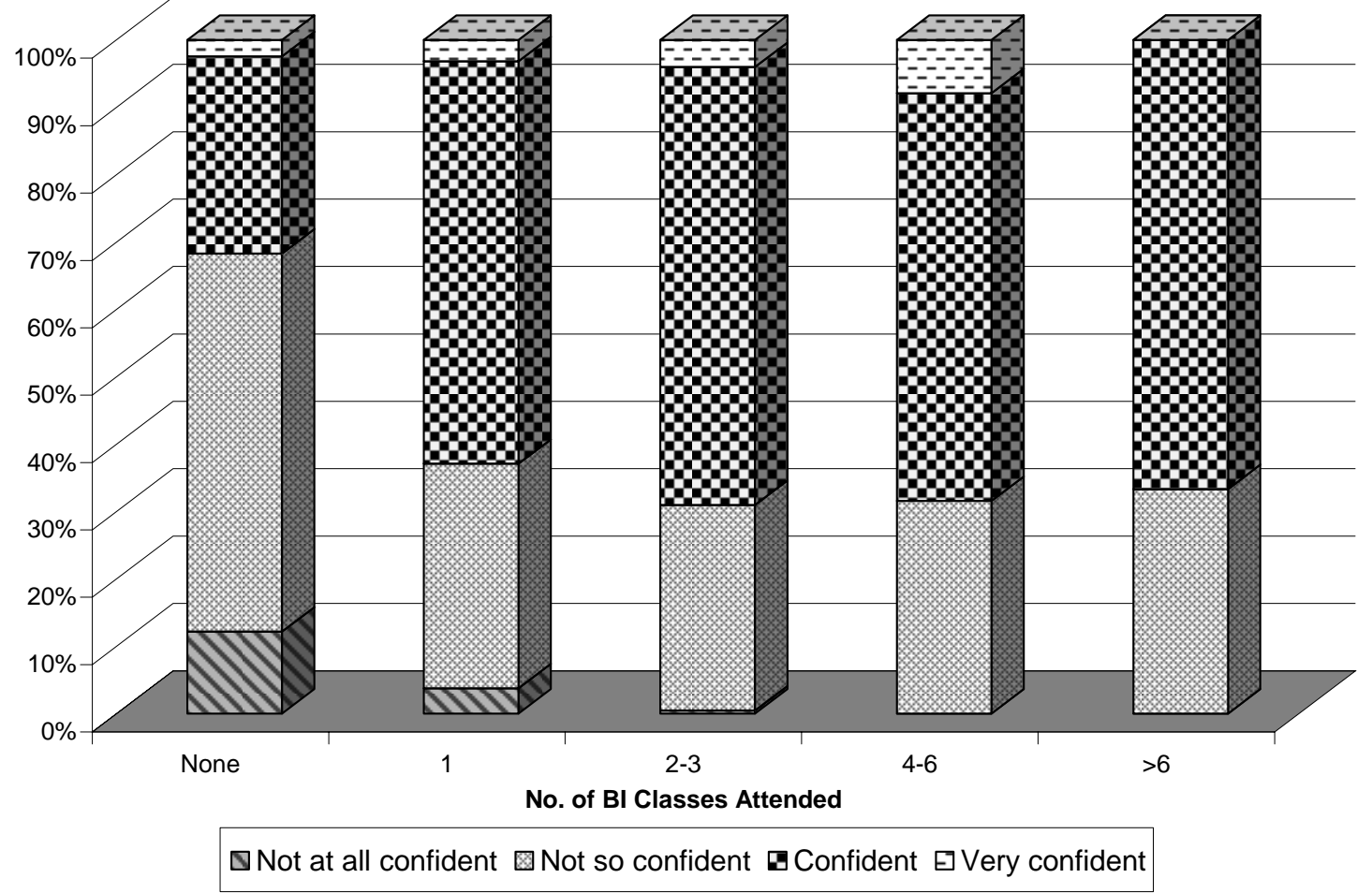


Figure 2

Relationship between Class Size and Retention Rate (No. of Class=15)

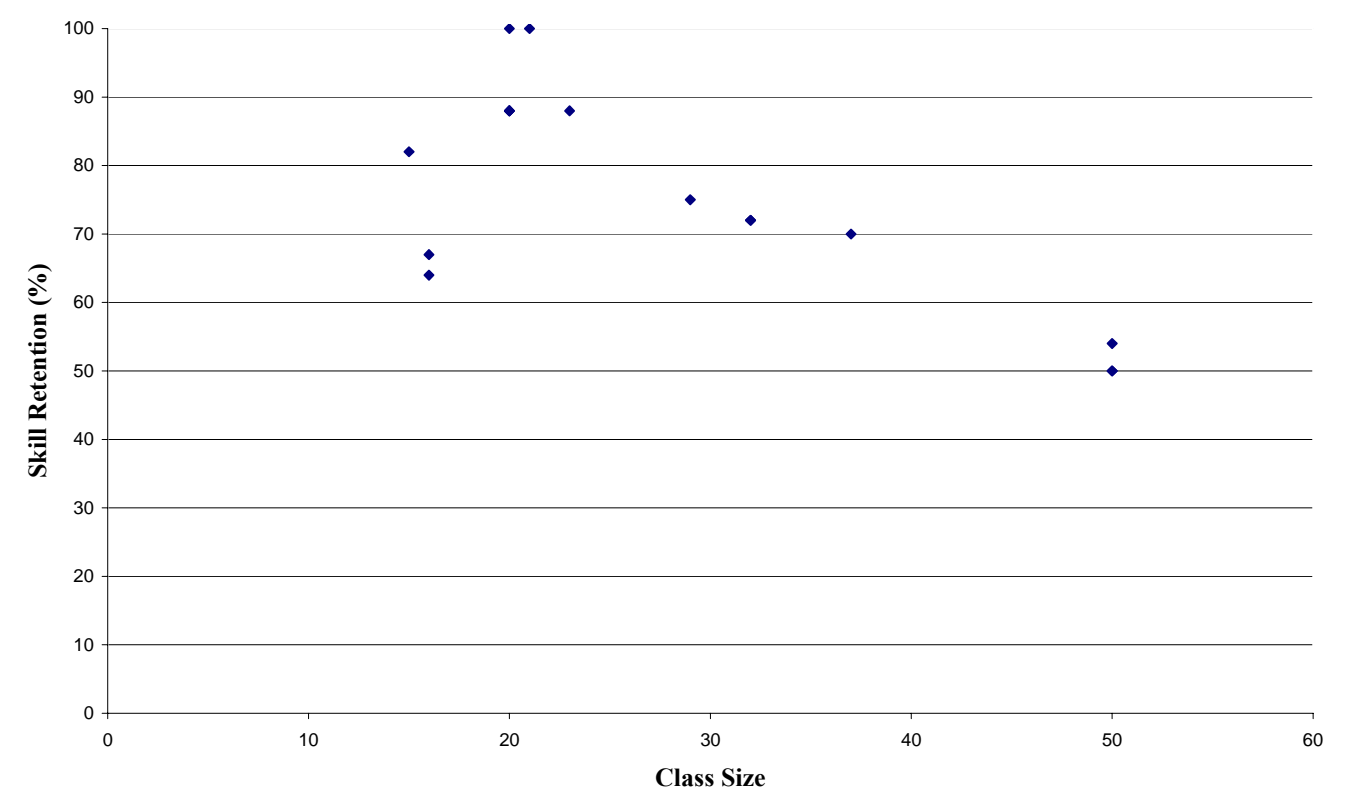

Figure 3

Relationship between Class Size and Class Rating (No. of Class=15)

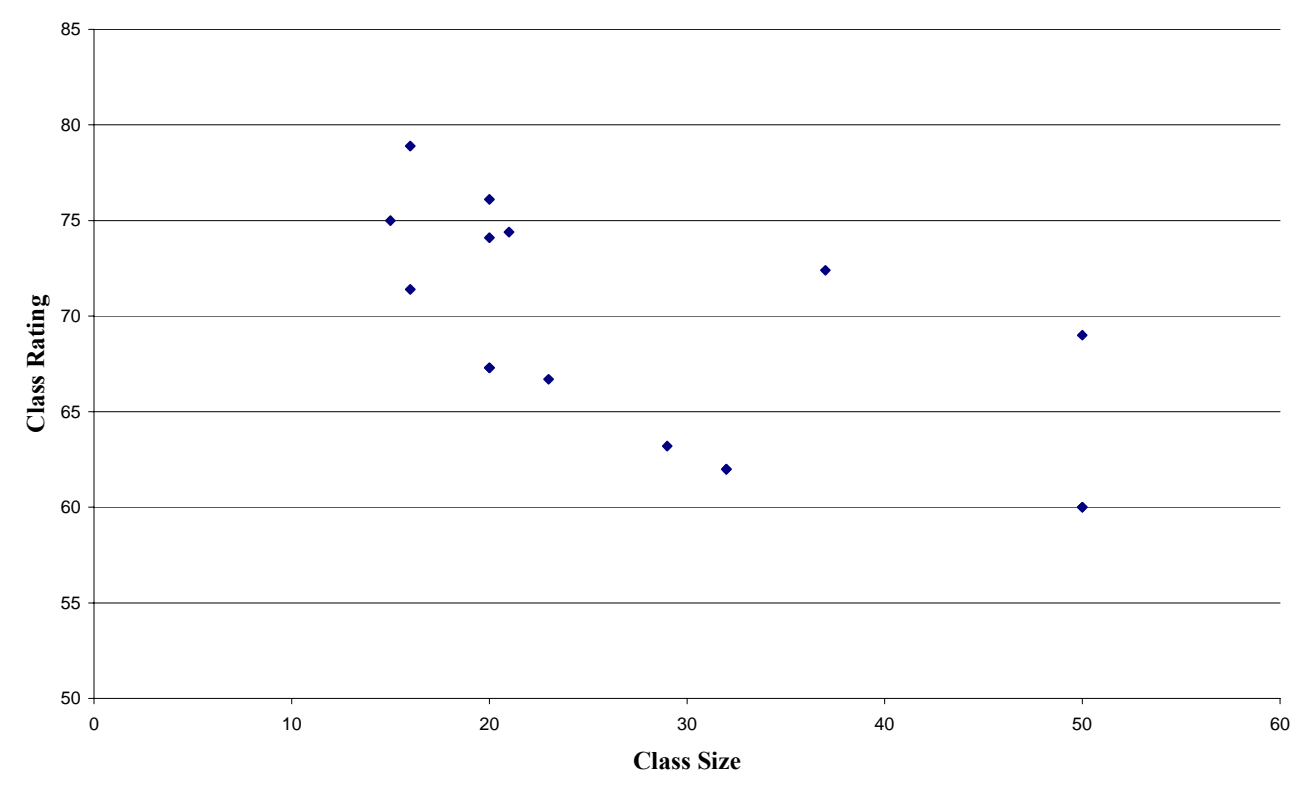




\section{Figure 4}

Relationship between Class Size and Instructor Rating (No. of Class=15)

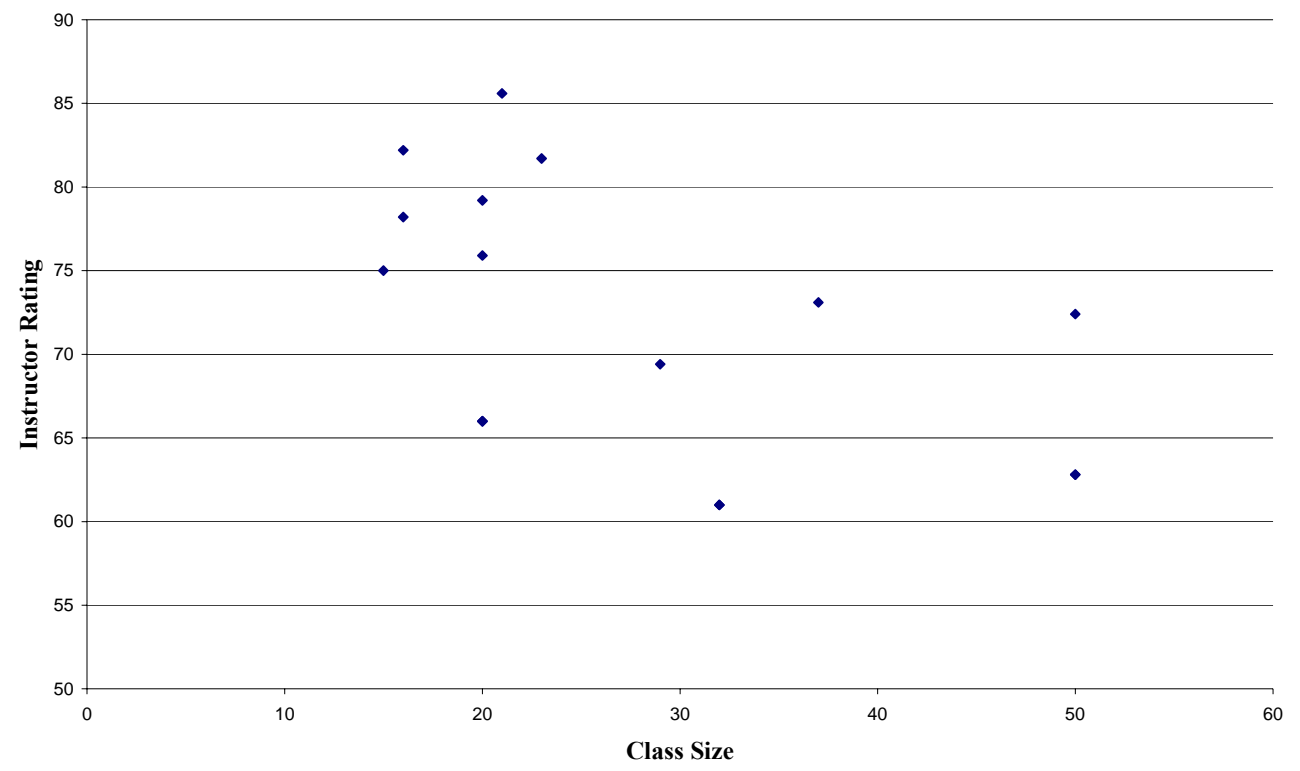

\section{Figure 5}

Relationship between Information Research Confidence and Retention Rate $(\mathbf{N}=\mathbf{3 8 3})$

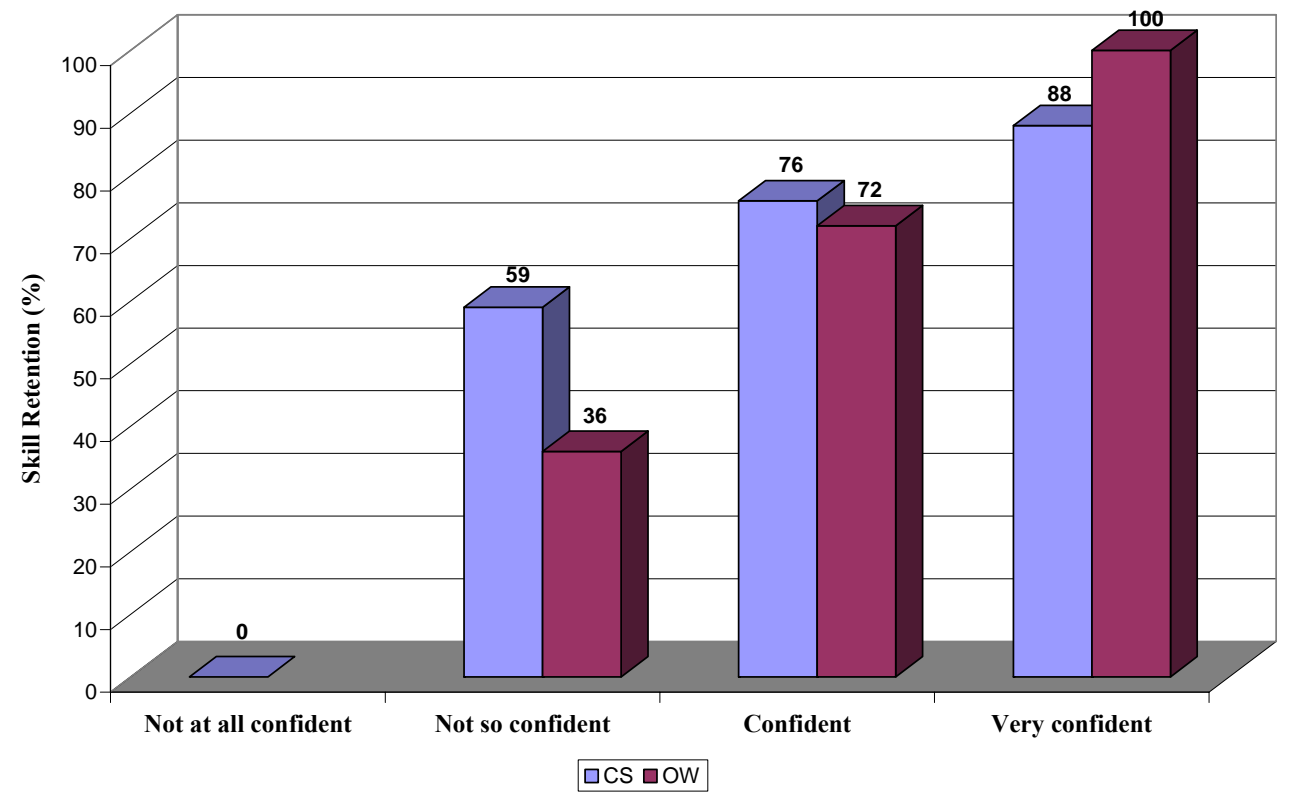


Figure 6

Relationship between Information Research Confidence and Class Rating ( $=395)$

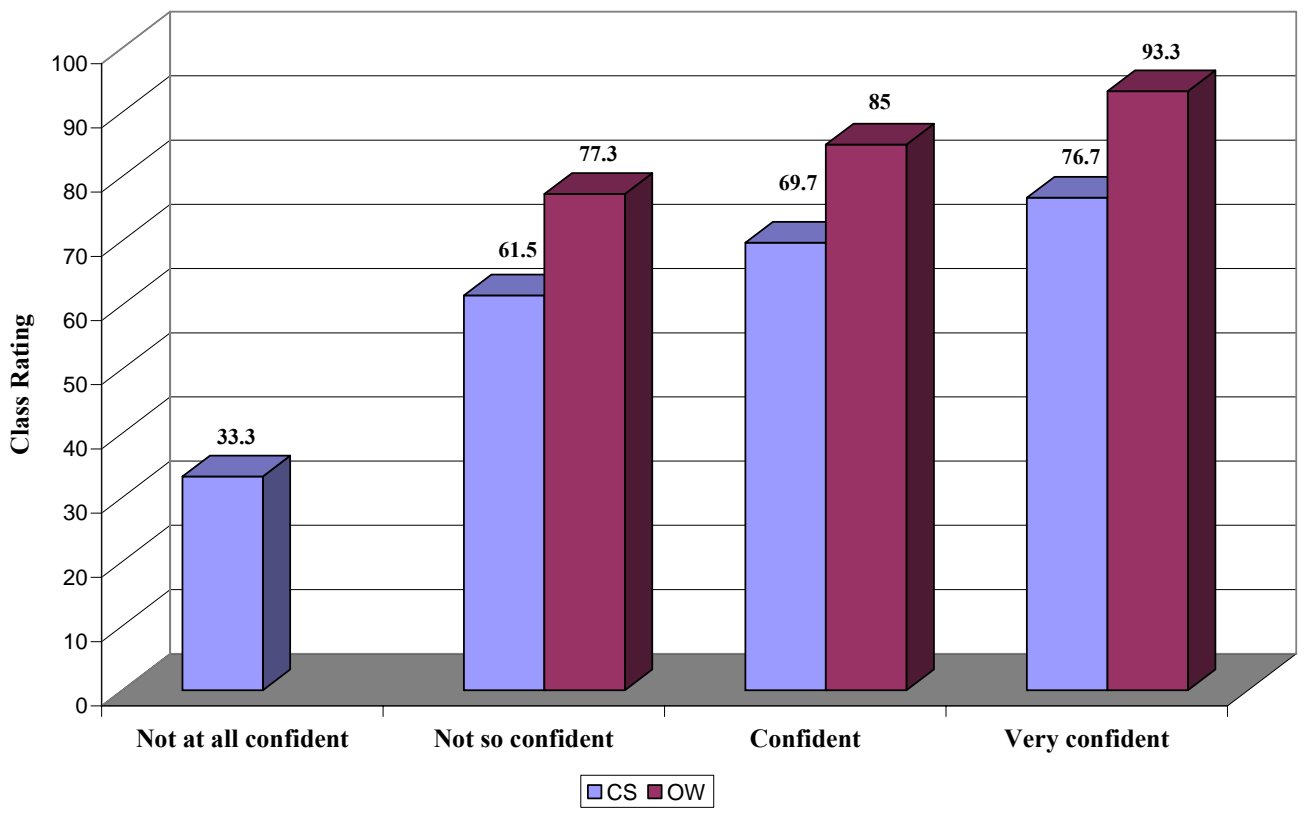

Figure 7

Relationship between Information Research Confidence and Instructor Rating $(\mathrm{N}=395)$

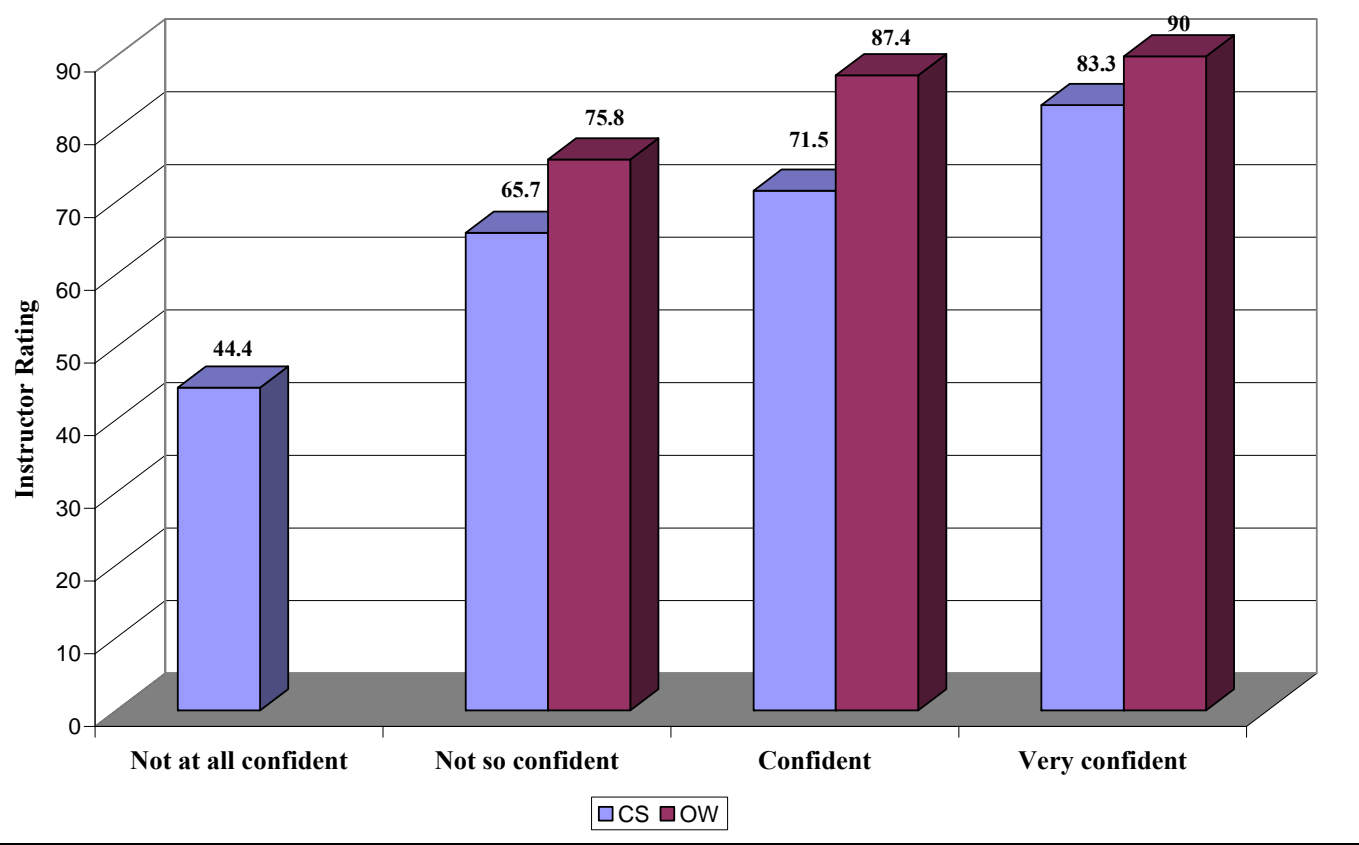

